\title{
Angiolymphoid hyperplasia with eosinophilia: An uncommon presentation and novel treatment of a rare disease
}

David Surprenant*1 ${ }^{* 1}$ Amanda Goslawski ${ }^{2}$, Karen Kagha ${ }^{3}$, Dana Griffin ${ }^{1}$, Kumaran Mudaliar $^{4}$, Kelli Hutchens ${ }^{4}$, Daniel Opel $^{1}$, Rebecca Tung ${ }^{1}$

${ }^{1}$ Division of Dermatology, Loyola University Medical Center, United States

${ }^{2}$ Stritch School of Medicine, Loyola University Medical Center, United States

${ }^{3}$ Department of Dermatology, Loma Linda University Health, United States

${ }^{4}$ Division of Pathology, Loyola University Medical Center, United States

Received: November 3, 2018

DOI: $10.5430 /$ crcp.v5n2p12
Accepted: December 26, 2018

Online Published: December 30, 2018

URL: https://doi.org/10.5430/crcp.v5n2p12

\begin{abstract}
Angiolymphoid hyperplasia with eosinophilia (ALHE) is an uncommon benign vascular proliferation characterized by isolated or grouped red-brown papules or nodules, most often located on the head or neck. Treatment of ALHE is difficult, with high recurrence rates reported across a myriad of different interventions. We report an atypical clinical presentation of ALHE that was successfully treated with a novel dual-therapeutic approach consisting of surgical excision followed by treatment with the pulsed dye laser.
\end{abstract}

Key Words: Angiolymphoid hyperplasia with eosinophilia, Pulsed dye laser, Excision

\section{CASE REPORT}

A 67-year-old Caucasian woman presented to our clinic with an eight-month history of three pruritic, pink papules located on her right upper chest, right flank, and right waistline. These lesions were initially thought to be secondary to arthropod assault. Treatment included topical and intralesional steroid preparations. However, the lesions persisted and slowly grew in size, becoming more nodular, firm, pruritic, and even somewhat painful. The patient was ultimately referred to our clinic for further workup.

Physical exam revealed three pink, firm, somewhat tender nodules located on her chest (see Figure 1), right flank, and right waistline (see Figure 2). Histological analysis (see Figures $3 \& 4$ ) of the lesion on her flank revealed superficial and deep perivascular and interstitial inflammation with lymphoid follicle formation and numerous eosinophils. In addition, the dermis showed a diffuse proliferation of vessels in the dermis lined by plump endothelial cells demonstrating cytoplasmic vacuolization. Immunohistochemical stains showed that the CD20+ B cells were predominantly confined to the lymphoid follicles. The reactive germinal centers were positive for CD10 and BCL-6 and were negative for BCL-2 (see Figure 5). The inter-follicular lymphocytic infiltrate was predominantly composed of T-cells positive for CD3, CD5, and CD7 with a CD4:CD8 ratio of 3:1 (see Figure 6).

\footnotetext{
*Correspondence: David Surprenant; Email: dsurpren@gmail.com; Address: Division of Dermatology, Loyola University Medical Center, United
} States. 
Findings were consistent with a diagnosis of angiolymphoid hyperplasia with eosinophilia (ALHE).

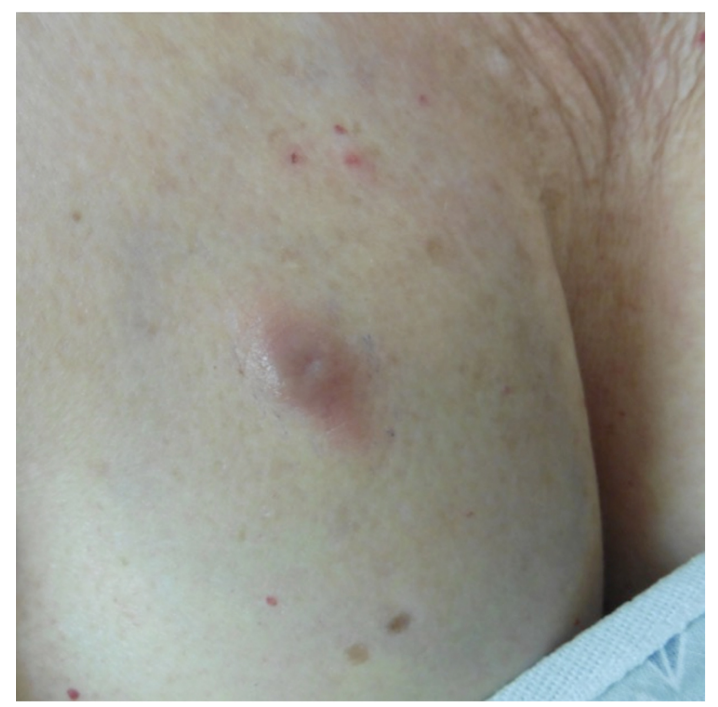

Figure 1. Pink, firm, somewhat tender nodule located on the patient's right chest at time of presentation

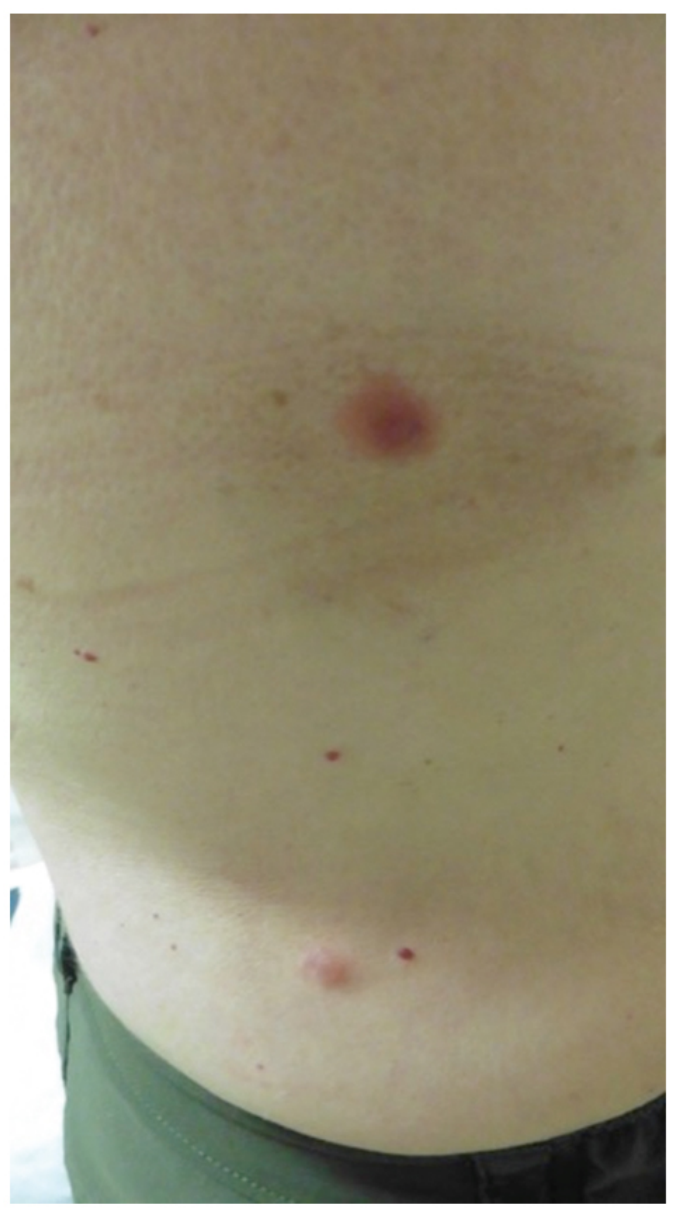

Figure 2. Two pink, firm, somewhat tender nodules located on the patient's right flank at time of presentation

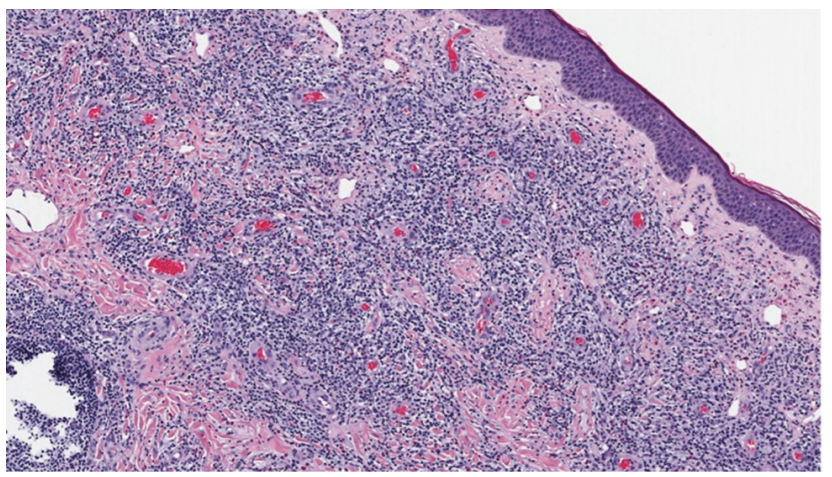

Figure 3. Low power analysis revealed superficial and deep perivascular and interstitial inflammation with lymphoid follicle formation and numerous eosinophils

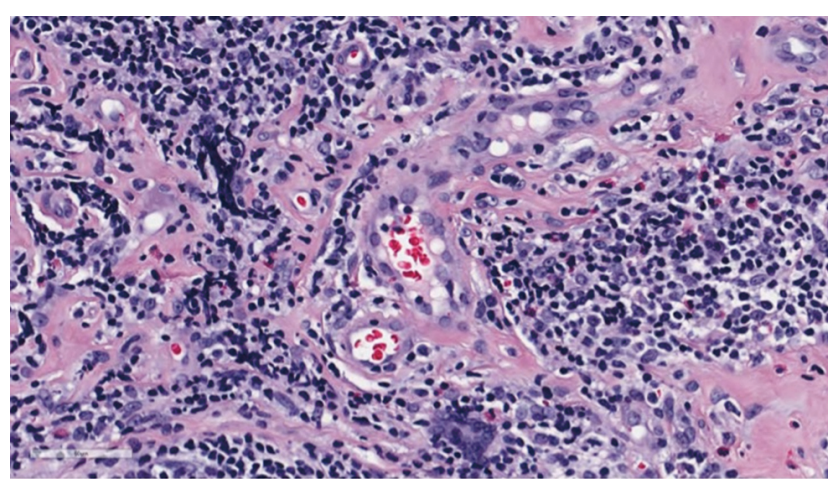

Figure 4. Higher power analysis showed a diffuse proliferation of vessels in the dermis lined by plump endothelial cells

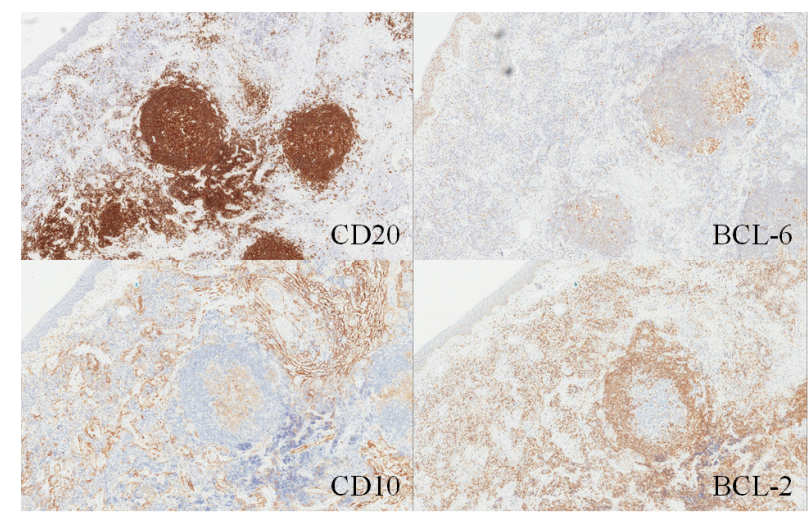

Figure 5. Immunohistochemical stains showed that the CD20+ B cells were predominantly confined to the lymphoid follicles. The reactive germinal centers were positive for CD10 and BCL-6 and were negative for BCL-2.

The three lesions were surgically excised (all in one sitting) and sent for histopathological review, confirming a diagnosis of ALHE for all three lesions. The healing excision sites including a one centimeter perimeter of normal skin were treated with five sessions of PDL (595 nm) therapy (Vbeam 
Perfecta, Candela Corp) at the following settings: 5-7 millimeter spot size, 6 millisecond pulse duration, 7-7.5 Joule fluence. At twenty-four months follow-up, there has been no recurrence of the lesions, and the patient experienced an exceptional cosmetic outcome.

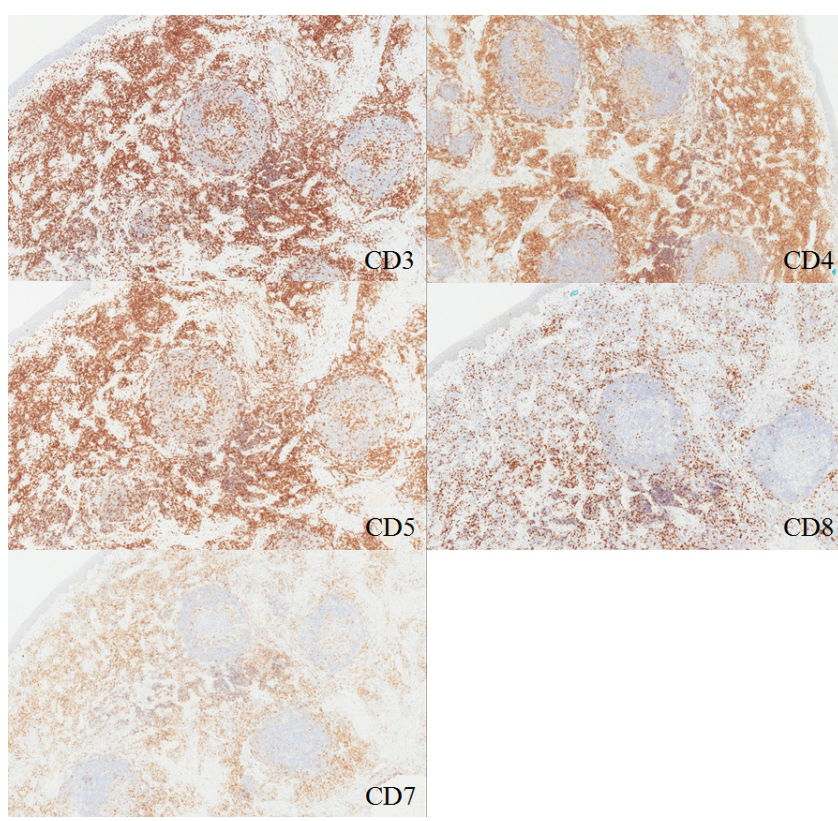

Figure 6. The inter-follicular lymphocytic infiltrate was predominantly composed of T-cells positive for CD3, CD5, and CD7 with a CD4:CD8 ratio of 3:1.

\section{Discussion}

Angiolymphoid hyperplasia with eosinophilia (ALHE) is an uncommon benign vascular proliferation characterized by isolated or grouped red-brown papules or nodules, most often located on the head or neck. ${ }^{[1-6]}$ Lesions have been described in various anatomical locations, but occurrence on the chest or flank, as found in our patient, is rare. ${ }^{[1,4,6,7]}$ A recent literature review of ALHE cases found only $0.6 \%$ and $0.9 \%$ of cases involved the abdomen and chest, respectively. ${ }^{[1]}$

Lesions are frequently asymptomatic, but may be pruritic or painful. ${ }^{[4,6,8]}$ While the incidence and prevalence of ALHE is unknown, ALHE is predominantly found in 20- to 50-year old adults, with a mean onset of 30 to 33 years of age..$^{[1,6,8]}$ Historically, ALHE was thought to be more common in females; ${ }^{[4,7-11]}$ however, a recent systemic review of the literature suggests there may be no clear gender predilection. ${ }^{[1]}$

The pathogenesis of ALHE is largely unknown. There are hypotheses that ALHE is a benign neoplasm of endothelial cells as well as thought that it may be an inflammatory vascular reaction to external trauma. ${ }^{[2,3,6-9]}$ There have also been reports of onset or worsening of ALHE nodules with initiation of oral contraceptives and during pregnancy, impli14 cating hyperestrogenemia in the pathogenesis. ${ }^{[8,12,13]} \mathrm{T}$-cell clonality has been demonstrated within a subset of cases, and there are a few published cases of synchronous T-cell lymphoma arising in ALHE patients, suggesting that ALHE could be a low-grade lymphoproliferative disorder or a specific variant of reactive lymphoid hyperplasia. ${ }^{[2,4,5,14]}$ Lastly, tortuous or damaged vessels can be seen at the base of lesions, suggesting a possible role of arteriovenous malformation in ALHE. ${ }^{[6,15]}$ Ultimately, the uncommon and benign nature of ALHE has contributed to a lack of disease understanding.

Histologically, ALHE is characterized by an expansive proliferation of small, capillary-sized vessels with thickened walls and characteristic plump epithelioid endothelial cells with cytoplasmic vacuolization. Surrounding the small vessels is a variably dense inflammatory infiltrate composed of lymphocytes with numerous eosinophils. Nodular lymphoid aggregates occasionally form reactive germinal centers. ${ }^{[4,9,12,16]}$

Given the uncommon nature of ALHE, there is a lack of evidence to guide therapy. While lesions are completely benign, they do not spontaneously regress and treatment is often undertaken for symptomatic and/or cosmetic reasons. Surgical excision is the mainstay of treatment, but recurrence is common. ${ }^{[1,4,14,17]}$ A recent review showed recurrence in $40 \%$ of cases following simple surgical excision. ${ }^{[1]}$ Numerous other therapeutic approaches have been described, including electrodessication, cryotherapy, interalesional steroid injections, and Moh's micrographic surgery, amongst others. ${ }^{[1,3,4,8,11,17-19]}$ Notably, treatment with vascular-specific pulsed dye lasers (PDL) has been shown effective, with a recurrence rate only slightly higher than surgical excision. ${ }^{[1,10,19-22]}$ PDL efficacy is not surprising, given the vascular nature of ALHE lesions. As a minimally invasive treatment option, PDL is a viable option, especially for patients who are not surgical candidates. Given the high recurrence rate following surgical excision alone, and the proven efficacy of PDL monotherapy, we decided to combine both treatment modalities. This novel, sequential dual-therapy approach has thus far yielded durable results at twenty-four months follow-up. Additionally, our patient had excellent cosmetic outcomes, as PDL treatment following surgery had the added benefit of minimizing scar discoloration.

This case highlights a unique presentation of ALHE and describes a novel treatment approach, utilizing sequential use of surgical excision followed by pulsed dye laser treatment. This combined treatment approach for ALHE should be considered by physicians when treating this rare, difficult to treat tumor.

\section{CONFlicts OF INTEREST Disclosure}

The authors declare that they have no competing interest. 


\section{REFERENCES}

[1] Adler BL, Krausz AE, Minuti A, et al. Epidemiology and treatment of angiolymphoid hyperplasia with eosinophilia (ALHE): A systematic review. J Am Acad Dermatol. 2016; 74: 506-512. PMid:26685720. https://doi.org/10.1016/j.jaad.2015.10.011

[2] Andreae J, Galle C, Magdorf K, et al. Severe atherosclerosis of the aorta and development of peripheral T-cell lymphoma in an adolescent with angiolymphoid hyperplasia with eosinophilia. Br J Dermatol. 2005; 152: 1033-8. PMid:15888166. https://doi .org/10.1 111/j.1365-2133.2005.06421.x

[3] Baum EW, Sams WM, Monheit GD. Angiolymphoid hyperplasia with eosinophilia. The disease and a comparison of treatment modalities. J Dermatol Surg Oncol. 1982; 8: 966-970. https: //doi.org/10.1111/j.1524-4725.1982.tb01077.x

[4] Chen JF, Gao HW, Wu BY, et al. Angiolymphoid hyperplasia with eosinophilia affecting the scrotum: A rare case report with molecular evidence of T-cell clonality. J Dermatol. 2010; 37: 355-359. PMid:20507406. https://doi.org/10.1111/j.1346-8138.20 10.00818. $\mathrm{x}$

[5] Gonzalez-Cuyar LF, Tavora F, Zhao XF, et al. Angiolymphoid hyperplasia with eosinophilia developing in a patient with history of peripheral T-cell lymphoma: evidence for multicentric T-cell lymphoproliferative process. Diagnostic Pathology. 2008; 29: 22. PMid:18510751. https://doi.org/10.1186/1746-1596-3-22

[6] Olsen TG, Helwig EB. Angiolymphoid hyperplasia with eosinophilia: a clinicopathologic study of 116 patients. J Am Acad Dermatol. 1985; 12: 781-796. https://doi .org/10.1016/S0190-9622(85) 700 98-9

[7] Trindade F, Haro R, Requena L. Giant angiolymphoid hyperplasia with eosinophilia on the chest. J Cutan Pathol. 2009; 36: 493-496. PMid:19278439. https://doi.org/10.1111/j.1600-0560.20 $08.01066 . \mathrm{x}$

[8] Don DM, Ishiyama A, Johnstone AK, et al. Angiolymphoid hyperplasia with eosinophilia and vascular tumors of the head and neck. Am J Otolaryngol. 1996; 17: 240-245. https ://doi .org/10.101 6/S0196-0709(96) 90088-5

[9] Buder K, Ruppert S, Trautmann A, et al. Angiolymphoid hyperplasia with eosinophilia and kimura's disease - a clinical and histopathological comparison. J Dtsch Dermatol Ges. 2014; 12: 224-228. https://doi.org/10.1111/ddg.12257

[10] Gupta G, Munro CS. Angiolymphoid hyperplasia with eosinophilia: successful treatment with pulsed dye laser using the double pulse technique. Br J Dermatol. 2000; 143: 214-5. https://doi.org/ 10.1046/j.1365-2133.2000.03632.x

[11] Zarrin-Khameh N, Spoden JE, Tran RM. Angiolymphoid hyperplasia with eosinophilia associated with pregnancy: a case report and review of the literature. Arch Pathol Lab Med. 2005; 129: 1168-71. PMid:16119993.

[12] Marcum CB, Zager JS, Bélongie IP, et al. Profound proliferating angiolymphoid hyperplasia with eosinophilia of pregnancy mimicking angiosarcoma. Cutis. 2011; 88: 122-8. PMid:22017064.

[13] Moy RL, Luftman DB, Nguyen QH, et al. Estrogen receptors and the response to sex hormones in angiolymphoid hyperplasia with eosinophilia. Arch Dermatol. 1992; 128: 825-828. https : //doi.org/10.1001/archderm.1992.01680160109016

[14] Kempf W, Haeffner AC, Zepter K, et al. Angiolymphoid hyperplasia with eosinophilia: evidence for a T-cell lympho-proliferative origin. Hum Pathol. 2002; 33: 1023-1029. https ://doi.org/10.1053/ hupa. 2002.128247

[15] Fontana SC, Borgstadt A, Fraga GR, et al. Angiolymphoid hyperplasia with eosinophilia with in a vascular malformation: Case report and review of the literature. Ann. Otol. Rhinol. Laryngol. 2016; 125 : 775-778. PMid:27141028. https://doi.org/10.1177/000348 9416646796

[16] Parmar NV, Sandu J, Kanwar AJ, et al. Angiolymphoid hyperplasia with eosinophilia of the infra-axillary region: Report of a case. Dermatol Online J. 2014; 20.

[17] Sarma DP, Chen M, Stevens T, et al. A woman with a lower lip nodule: What is your diagnosis? Patholog Res Int. 2011; 2011. http://dx.doi.org/10.4061/2011/656394

[18] Miller CJ, Michael DI, Christie TA. Mohs micrographic surgery for angiolymphoid hyperplasia with eosinophilia. Dermatol Surg. 2004; 30: 1169-1173. PMid:15274714. https ://doi.org/10.1111/j . 1524-4725.2004.30349.x

[19] Rohrer TE, Allan AE. Angiolymphoid hyperplasia with eosinophilia successfully treated with a long-pulsed tunable dye laser. Dermatol Surg. 2000; 26: 211-214. https://doi .org/10.1046/j.1524-4 725.2000.09223.x

[20] Abrahamson TG, Davis DA. Angiolymphoid hyperplasia with eosinophilia responsive to pulsed dye laser. J Am Acad Dermatol. 2003; 49: 195-196. PMid:12894122. https://doi.org/10.106 $7 / \mathrm{mjd} .2003 .314$

[21] Angel CA, Lewis AT, Griffin T, et al. Angiolymphoid hyperplasia successfully treated with an ultralong pulsed dye laser. Dermatol Surg. 2005; 31: 713-716. https ://doi .org/10.1111/j .1524-4 725.2005 .31621

[22] Vanhooteghem O, Flagothier C, De La Brassinne M. Angiolymphoid hyperplasia with eosinophilia of the scalp: promising results of longpulsed tunable dye laser treatment. J Eur Acad Dermatol Venereol. 2009; 23: 954-5. PMid:19453797. https://doi.org/10.1111/ j.1468-3083.2009.03141.x 